\title{
BMJ Open Long fusion correction of degenerative adult spinal deformity and the selection of the upper or lower thoracic region as the site of proximal instrumentation: a systematic review and meta-analysis
}

\author{
Xin Fu, ${ }^{1}$ Xiao-Lei Sun, ${ }^{1}$ Jonathan A Harris, ${ }^{2}$ Sun-Ren Sheng, ${ }^{3}$ Hua-Zi Xu, ${ }^{3}$ \\ Yong-Long Chi, ${ }^{3} \mathrm{Ai}-\mathrm{Min} \mathrm{Wu}^{3}$
}

To cite: Fu X, Sun X-L, Harris $\mathrm{JA}$, et al. Long fusion correction of degenerative adult spinal deformity and the selection of the upper or lower thoracic region as the site of proximal

instrumentation: a systematic review and meta-analysis. BMJ Open 2016;6:e012103. doi:10.1136/bmjopen-2016012103

- Prepublication history and additional material is available. To view please visit the journal (http://dx.doi.org/ 10.1136/bmjopen-2016012103).

Received 30 March 2016 Revised 11 October 2016 Accepted 13 October 2016

CrossMark

For numbered affiliations see end of article.

Correspondence to Dr. Ai-Min Wu;

Department of Orthopaedics, Second Affiliated Hospital of Wenzhou Medical University, Zhejiang Spinal Research Centre, Wenzhou, Zhejiang, China; aiminwu@163.com

\section{ABSTRACT}

Objective: The aim of this study was to compare outcomes when the upper and lower thoracic regions were used as the site of proximal instrumentation to treat adult spinal deformity.

Methods: MEDLINE, Embase and Cochrane library searches were performed to identify studies that compared outcome measures when the upper and lower thoracic vertebrae (UTV and LTV, respectively) were used as the site of proximal instrumentation. The weighted mean difference (WMD) was calculated for continuous outcomes, and the relative risk (RR) was calculated for dichotomous outcomes.

Results: Seven articles ( $\mathrm{n}=554$ patients) met the final inclusion criteria, and we compared the outcome measures of a long fusion extending to the upper and lower thoracic regions. The pooled analysis revealed that extending fixation into the upper thoracic region decreased the risk of proximal junctional kyphosis (PJK) revision surgery (RR: $0.36,95 \% \mathrm{Cl} 0.14$ to 0.90 , $p<0.05$ ). The operation time (WMD: $0.93,95 \% \mathrm{Cl} 0.48$ to $1.39, p<0.05$ ) and estimated blood loss (WMD: $0.59,95 \% \mathrm{Cl} 0.33$ to $0.85, \mathrm{p}<0.05$ ) were significantly greater in the UTV group than in the LTV group. No significant differences were found in the Scoliosis Research Society pain, self-image, function, mental health, subtotal, satisfaction or total scores; the total number of complications or the total number of revision surgeries.

Conclusions: Long posterior fixation extending into the upper thoracic region reduces the incidence of revision surgery related to PJK; however, it increased the operative level resulting in a longer operative time and greater estimated blood loss. This initial analysis indicates that extending fixation to the upper thoracic region is appropriate for patients who are likely to develop PJK following initial scoliosis correction.

\section{INTRODUCTION}

The global incidence of adult spinal deformity (ASD) is increasing as the elderly

\section{Strengths and limitations of this study}

- This is the first meta-analysis to compare the efficacy and safety of the upper and lower thoracic vertebrae (UTV and LTV, respectively) as the upper instrumented vertebra for correction of degenerative adult spinal deformity.

- The quality of each included study was assessed by methodological index for non-randomised studies and with high scores.

- No obvious publication bias was observed by Begg's and Egger's tests.

- Most of the pooled results showed good consistency (low heterogeneity among studies).

- No randomised controlled studies were found in this review, and there was no consistent definition of which vertebra constituted UTV or LTV among studies.

population grows. When non-operative treatment fails, ASD patients require surgical intervention. ${ }^{1}$ The main goals of surgical treatment for ASD are decompression and the re-establishment of coronal and sagittal balance. $^{2}{ }^{3}$ Selecting the surgical plan for ASD is a challenge for spinal surgeons. ${ }^{4-6}$

Posterior long fixation and fusion from the thoracic spine to the sacrum is one of the most common surgical treatments for ASD. ${ }^{7-9}$ However, there is some debate regarding the most appropriate upper instrumented vertebra for thoracolumbosacral fusion. ${ }^{10}$ Suk has suggested that fusing the upper thoracic vertebrae (UTV) rather than T10 might decrease adjacent segment disease, whereas Madjetko has reported that patients might benefit from upper thoracic spinal fusion.

To the best of our knowledge, there is no standard guideline for whether the UTV or lower thoracic vertebrae (LTV) are better for ASD treatment. In this meta-analysis, we 
compared the peri-operative parameters, clinical and radiological outcomes, complications and need for revision between the UTV and LTV as the site of the upper instrumented vertebra for ASD.

\section{MATERIALS AND METHODS}

This study was performed according to the preferred reporting items of the systematic review and metaanalyses (PRISMA) guidelines (see online supplementary checklist $\mathrm{S} 1) .{ }^{11}$

\section{Search strategy}

A comprehensive MEDLINE, Embase and Cochrane Library search was performed on 31 July 2016, by two independent authors (XF and XLS) using various combinations of the following search terms: "proximal fusion level" or "upper instrumented vertebra" or "proximal junctional kyphosis", or "upper instrumented thoracic vertebra" and "degenerative lumbar deformity", or "adult lumbar deformity", or "adult spinal deformity", "degenerative lumbar scoliosis", or "adult scoliosis". The search strategy developed for use with the MEDLINE database is shown in online supplementary table S1. Peer-reviewed articles reporting outcome measures for thoracolumbar and thoracolumbosacral instrumentation correction of ASD were collected. The reference lists of key articles were examined for eligible studies, and searches were performed with Google Scholar to avoid initial omissions.

\section{Inclusion criteria}

All studies comparing the UTV and LTV as the upper instrumented vertebra for ASD were included. The inclusion criteria for the studies were as follows: (1) a minimum age of 18 years for all patients; (2) ASD, adult lumbar deformity or degenerative scoliosis as the primary indication for surgery; (3) a comparison of the UTV and LTV as the site of the upper instrumented vertebra for the treatment of ASD; and (4) a final postoperative follow-up of at least 12 months.

The following exclusion criteria were used: (1) case reports or case studies without comparisons; (2) data related to peri-operative parameters, clinical and radiological outcomes, complications and revisions that could not be extracted or calculated; and (3) a follow-up of $<12$ months. If multiple studies reported the same cohort of patients, only the most recent publication with the largest sample size was included.

\section{Data items and extraction}

The data parameters were predetermined and reported in the reference literature. The data extraction was performed in two phases by two reviewers (XF and XLS) and subsequently assessed for consistency by a third reviewer (AMW). A standardised form was used that included the following items: (1) basic characteristics, such as patient sample size, year of publication, country of the study, age and gender descriptors, and final postoperative follow-up period; (2) peri-operative data, such as operative time and estimated blood loss; (3) clinical outcomes, such as the Scoliosis Research Society (SRS) pain level, self-image, function, mental health, subtotal, satisfaction, and total scores and the Oswestry disability index (ODI) score; (4) radiographic outcomes, including thoracic kyphosis (TK), thoracolumbar kyphosis (TLK), lumbar lordosis (LL), proximal junctional kyphotic angle, C7 sagittal vertical axis (C7SVA) and pelvic incidence; and (5) postoperative complications and revisions related to proximal junctional kyphosis $(\mathrm{PJK})$, pseudarthrosis and hardware implant failure.

\section{Quality assessment of the included studies}

The quality of the included studies was assessed based on the methodological index for non-randomised studies (MINORS). ${ }^{12}$ Twelve items were scored as ' 0 ' (not reported), ' 1 ' (reported but inadequate) or '2' (reported and adequate). Two independent reviewers (XF and XLS) assessed the quality of the included studies.

\section{Statistical analysis}

The data suitable for the meta-analysis were evaluated with STATA software (V.12.0; StataCorp, College Station, Texas, USA). The weighted mean difference (WMD) was calculated for continuous outcomes, and the relative risk (RR) was calculated for dichotomous outcomes. A random-effect model was used to perform the pooled analysis. ${ }^{13-15}$ Heterogeneity was defined if the $\chi^{2}$ test was $<0.10$ or the $\mathrm{I}^{2}$ test was $>30 \%$. If heterogeneity was observed, a further sensitivity analysis was involved to omit one study and evaluate whether the other results were significantly affected. The publication bias was analysed using Begg's and Egger's tests.

\section{RESULTS}

\section{Literature search}

A total of 254 potential records were identified through MEDLINE $(n=158)$, Embase $(n=94)$ and the Cochrane library $(n=2)$. After 43 duplicate articles were excluded, 211 articles were screened for titles and abstracts, which eliminated 180 articles. One article ${ }^{16}$ was added through a Google Scholar search. In total, 32 full-text articles were assessed for eligibility, and 25 were excluded because they were a 'case report or case study without a comparison, a review article, a debate, an article from the same site as another included study, or other reasons'. Finally, seven non-random comparative studies ${ }^{16-22}$ were included in this meta-analysis. The included studies are shown in figure 1 (PRISMA flow diagram).

\section{Study characteristics}

The characteristics of the seven non-randomised controlled trial (RCT) studies are listed in table 1.We did not find an RCT study comparing the UTV and LTV as the site of the upper instrumented vertebra for the 


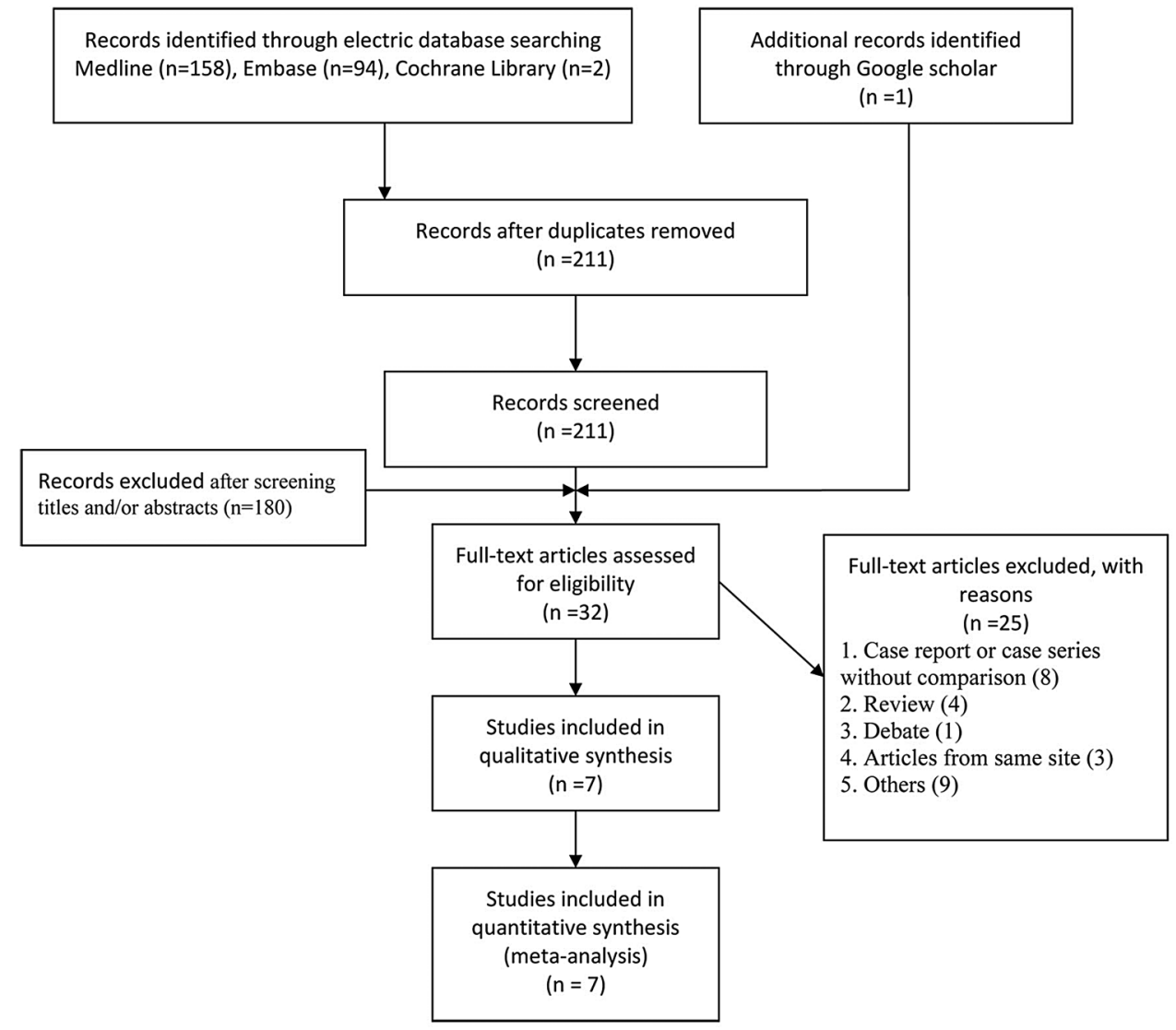

Figure 1 PRISMA flow diagram illustrating the selection of studies for inclusion. PRISMA, preferred reporting items of the systematic review and meta-analyses.

treatment of ASD. Cho et $a l^{17}$ and Kim $e t a l^{20}$ separated the proximal instrumented vertebrae data into three groups (T9-T10, T11-T12 and L1-L2). For this study, the T11-T12 and L1-L2 groups were included in the LTV data set. There were 232 patients in the UTV group and 322 in the LTV group; more than 2 years of follow-up data were available for both groups.

\section{Quality assessment}

The methodological quality assessment of the seven included studies is summarised in table 2. Each of the seven studies clearly stated the aim of the study, and the participants were consecutive patients. The data in the study of O'Shaughnessy et $a l^{19}$ were collected prospectively, while in the other studies, the data were retrospectively collected. In the study of Kim $e t a l,{ }^{20}$ some patients did not finish the SRS score assessment; therefore, we assigned that study a score of ' 1 ' for the 'loss to follow-up less than 5\%' item. The scores ranged from 16 to 20 , with a median value of 17.9 . Publication bias was analysed using Begg's and Egger's tests; all of the $p$ values were $>0.05$, and no publication bias was observed (see online supplementary table $\mathrm{S} 2$ ).

\section{Operative time and estimated blood loss}

Four studies ${ }^{16} 181921$ reported the mean values and SDs for operative time and estimated blood loss. The meta-analysis showed that the UTV group had a longer operative time (WMD: $0.93,95 \%$ CI 0.48 to 1.39 , $\mathrm{p}<0.05$ ) and a greater estimated blood loss (WMD: 0.59, $95 \%$ CI 0.33 to $0.85, \mathrm{p}<0.05)$ compared with the LTV group, with both parameters showing a statistically significant difference (figure 2). No obvious heterogeneity was observed, with $\mathrm{I}^{2}=4.4 \%, \mathrm{p}=0.371$ in the UTV group and $\mathrm{I}^{2}=0.0 \%, \mathrm{p}=0.522$ in the LTV group.

\section{Clinical outcomes}

The studies of O'Shaughnessy et al, ${ }^{19}$ Kim et $a l^{20}$ Fujimori et $a l^{21}$ and Yagi et $a l^{16}$ reported SRS scores, including pain $(-0.07,95 \%$ CI -0.31 to $0.16, p>0.05)$, self-image $(-0.07,95 \%$ CI -0.29 to $0.15, \mathrm{p}>0.05)$, function $(-0.03,95 \%$ CI -0.22 to $0.16, p>0.05)$, mental health $(-0.30,95 \%$ CI -0.63 to $0.02, \mathrm{p}>0.05)$, subtotal $(-0.10,95 \%$ CI -0.29 to $0.09, \mathrm{p}>0.05)$, satisfaction $(0.13$, $95 \%$ CI -0.13 to $0.40, \mathrm{p}>0.05)$ and total scores $(-0.03$, $95 \%$ CI -0.23 to $0.18, p>0.05)$. No statistically significant differences were found between the UTV and LTV groups (figure 3 ). The $\mathrm{I}^{2}$ of the SRS self-image score was $2.4 \%$, and the $\mathrm{I}^{2}$ of the SRS mental health score was $24.2 \%$; all others were $0.0 \%$.

The studies of O'Shaughnessy et al, ${ }^{19}$ Fujimori et al, ${ }^{21}$ Yagi $e t a l^{16}$ and Du $e t a l^{22}$ reported the ODI score results. The meta-analysis did not find a statistically significant difference between the UTV and LTV groups (WMD: 


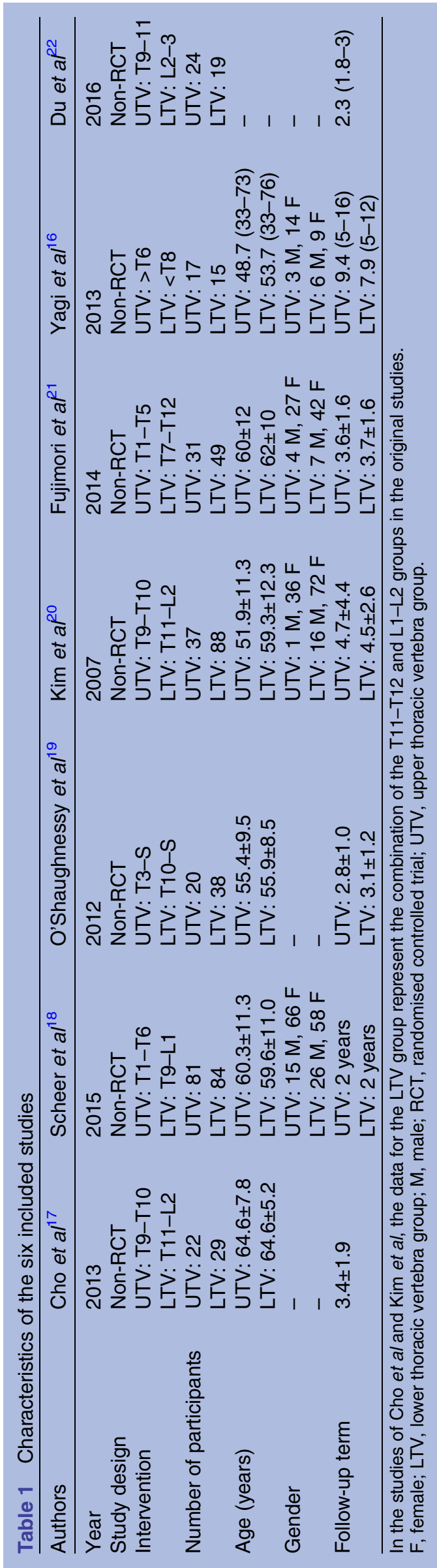

$2.05,95 \%$ CI -2.49 to 6.60 ), and no heterogeneity was observed $\left(\mathrm{I}^{2}=0.0 \%, \mathrm{p}=0.725\right.$; figure 4$)$.

\section{Radiographic outcomes}

The meta-analysis of TK showed no significant difference between the UTV and LTV groups (WMD: 2.37, $95 \%$ CI 1.33 to 6.08 ), and no heterogeneity was observed $\left(\mathrm{I}^{2}=0.0 \%, \mathrm{p}=0.404\right.$; figure 5$)$.

No significant differences were found in the meta-analyses of TLK, LL, PJK angle, C7SVA or pelvic incidence; all were observed to have heterogeneity, with $\mathrm{I}^{2}=70.2 \%, 46.2 \%, 81.8 \%, 89.8 \%$ and $40.5 \%$, respectively. The sensitivity analysis of the parameters revealed no significant changes in LL, PJK angle or pelvic incidence. The omission of Cho et $a l^{17}$ was found to significantly affect the C7SVA results (see online supplementary figure S1) and changed the WMD from -4.05 (95\% CI -28.51 to 20.42$)$ to -17.67 (95\% CI -42.01 to 6.67 ; figure 5).

\section{Complications and revision}

The meta-analyses of the total complications and total revisions revealed no significant difference between the UTV and LTV groups, with RRs of 0.89 (95\% CI 0.61 to 1.29 ) and 0.70 (95\% CI 0.43 to 1.14 ), respectively. The subgroup meta-analysis for revision surgery revealed that the UTV group had a lower risk of revision for PJK compared with the LTV group, with an RR of 0.36 (95\% CI 0.14 to 0.90$)$; no significant differences in pseudarthrosis or hardware implant failure for revision were found (RRs: 1.27 (95\% CI 0.72 to 2.23) and 1.12 (95\% CI 0.30 to 4.12), respectively; figure 6). Heterogeneity was observed in the meta-analyses of total revision and hardware implant failure for revision, with $\mathrm{I}^{2}=50.3 \%$ and $\mathrm{p}=0.090$ and $\mathrm{I}^{2}=55.0 \%$ and $\mathrm{p}=0.109$, respectively. The sensitivity analyses of these parameters showed no significant change when any one study was omitted (see online supplementary figure S1).

\section{DISCUSSION}

Degenerative spinal deformity is typically observed in patients over 60 years of age. ${ }^{123-25}$ The symptoms of ASD vary from mild back pain without radiculopathy to severe back pain with radiculopathy, neurogenic claudication and even ambulatory intolerance. ${ }^{26} \mathrm{~A}$ positive radiographic test reveals coronal or sagittal imbalance or both, with or without spinal stenosis. ${ }^{27}$ Decreased LL and sagittal balance are the main causes of pain and functional loss. ${ }^{28} 29$ The aims of surgical treatment are decompression, pain relief and the re-establishment of coronal and sagittal balance. ${ }^{3} 30-32$

Posterior long fusion has been the primary surgical treatment for ASD ${ }^{33}$ however, debate continues on the selection of the best proximal fused vertebra. ${ }^{10}{ }^{34}$ Using the LTV as the site of the upper instrumented vertebra has been reported to cause a high prevalence of $\mathrm{PJK},{ }^{35-37}$ and some surgeons suggest using the UTV for a longer 
Table 2 Quality assessment of six included studies

\begin{tabular}{|c|c|c|c|c|c|c|c|}
\hline $\begin{array}{l}\text { Methodological item for non-randomized } \\
\text { studies }\end{array}$ & $\begin{array}{l}\text { Cho } \\
\text { et } a i^{17}\end{array}$ & $\begin{array}{l}\text { Scheer } \\
\text { et } a l^{18}\end{array}$ & $\begin{array}{l}\text { O'Shaughnessy } \\
\text { et } \text { al }^{19}\end{array}$ & $\begin{array}{l}\text { Kim } \\
\text { et } a P^{20}\end{array}$ & $\begin{array}{l}\text { Fujimori } \\
\text { et }\left.a\right|^{21}\end{array}$ & $\begin{array}{l}\text { Yagi } \\
\text { et } \text { al }^{16}\end{array}$ & $\begin{array}{l}\text { Du } \\
\text { et } a P^{22}\end{array}$ \\
\hline 1. A clearly stated aim & 2 & 2 & 2 & 2 & 2 & 2 & 2 \\
\hline 2. Inclusion of consecutive patients & 2 & 2 & 2 & 2 & 2 & 2 & 2 \\
\hline 3. Prospective collection of data & 0 & 0 & 2 & 0 & 0 & 0 & 0 \\
\hline 4. End points appropriate to the aim of the study & 2 & 2 & 2 & 2 & 2 & 2 & 2 \\
\hline 5. Unbiased assessment of the study end point & 0 & 0 & 1 & 0 & 0 & 0 & 0 \\
\hline $\begin{array}{l}\text { 6. Follow-up period appropriate to the aim of the } \\
\text { study }\end{array}$ & 2 & 2 & 2 & 2 & 2 & 2 & 2 \\
\hline 7. Loss to follow-up $<5 \%$ & 2 & 2 & 2 & 1 & 2 & 2 & 2 \\
\hline 8. Prospective calculation of the study size & 0 & 0 & 0 & 0 & 0 & 0 & 0 \\
\hline 9. An adequate control group & 2 & 2 & 2 & 2 & 2 & 2 & 2 \\
\hline 10. Contemporary groups & 2 & 2 & 2 & 2 & 2 & 2 & 2 \\
\hline 11. Baseline equivalence of groups & 2 & 2 & 1 & 1 & 1 & 2 & 2 \\
\hline 12. Adequate statistical analyses & 2 & 2 & 2 & 2 & 2 & 2 & 2 \\
\hline Total scores & 18 & 18 & 20 & 16 & 17 & 18 & 18 \\
\hline
\end{tabular}

Figure 2 The meta-analysis results for operative time and estimated blood loss. The UTV group had a longer operative time (WMD: $0.93,95 \% \mathrm{Cl} 0.48$ to 1.39 , $\mathrm{p}<0.05)$ and greater estimated blood loss (WMD: 0.59, 95\% Cl 0.33 to $0.85, p<0.05)$ than the LTV group, and both parameters showed statistically significant differences. LTV, lower thoracic vertebra; UTV, upper thoracic vertebra; WMD, weighted mean difference.

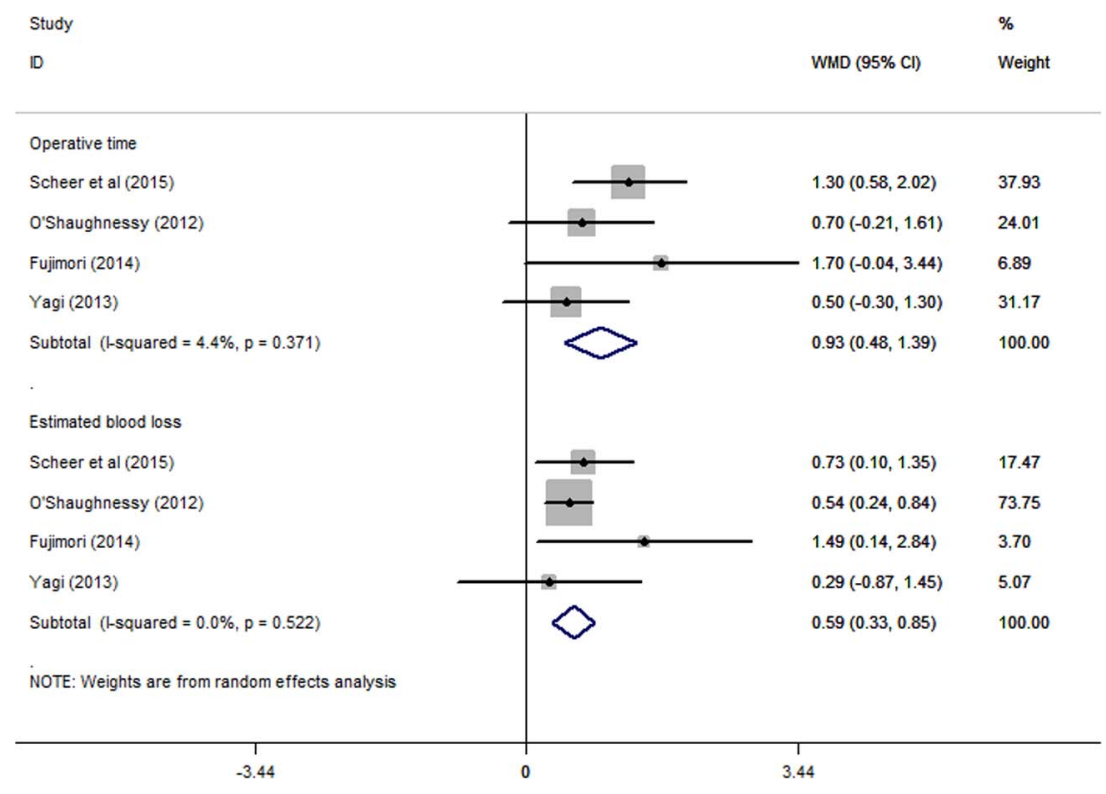

fusion with the aim of reducing the incidence of PJK and the need for revision.

Scheer et $a l^{18}$ reported that ASD patients undergoing posterior fixation extending into the upper thoracic region have better sagittal spino-pelvic alignment and a lower risk of revision surgery; however, O'Shaughnessy et $a l^{19}$ and $\mathrm{Kim}$ et al ${ }^{20}$ have reported conflicting results. In this meta-analysis, we synthesised data on complications and revision surgery, and no significant differences were found between the UTV and LTV groups. A further subgroup analysis of the various reasons for revision surgery was performed and indicated that the UTV group had a significantly lower risk of revision because of PJK (figure 6). The T11-L2 segment has always been regarded as the junctional spinal segment, and the T1T10 segment is supported by the true ribs, whereas the T11-T12 segment has floating ribs without costosternal articulation. The biomechanics differ significantly between the rigid thoracic spine and the flexible lumbar spine in the T11-L2 region. This region has been reported as having a high incidence of fractures and kyphosis. $^{38} 39$ In addition, in the studies of Cho et al ${ }^{17}$ and O'Shaughnessy et $a l^{19}$ the TLK was higher in the LTV group than in the UTV group; this finding supports the possibility that patients with postoperatively higher TLK are more likely to develop PJK and suggests that posterior fixation extending into the upper thoracic region could maintain sagittal alignment in the thoracolumbar region. Hyun et $a t^{40}$ reported that PJK patients had lower thoracolumbar muscularity and that lower thoracolumbar muscularity may induce higher TLK, resulting in a higher risk of PJK.

Although the UTV group had a decreased incidence of revision surgery for PJK, several deficiencies 


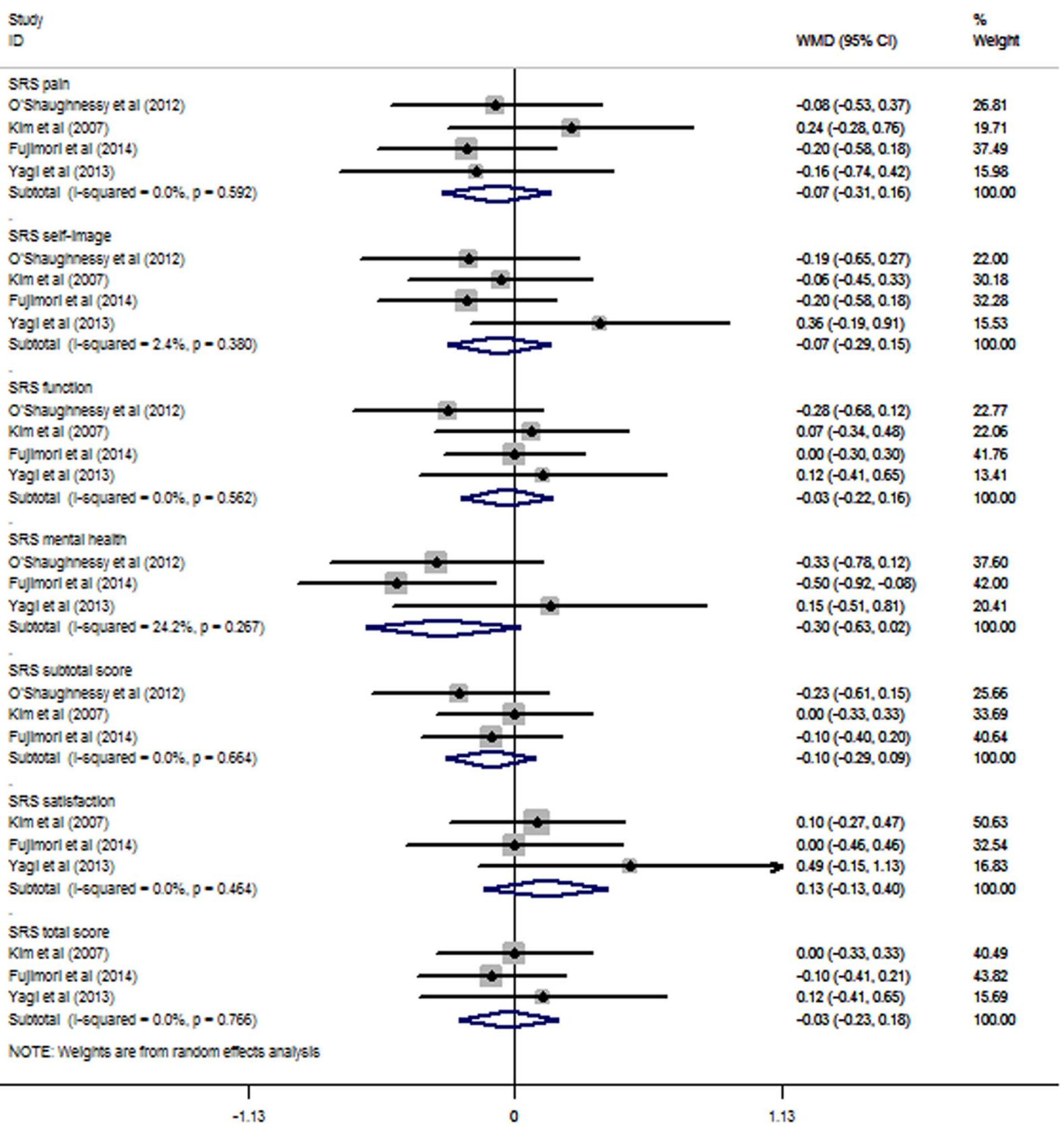

Figure 3 The meta-analysis results for the SRS outcomes. No statistically significant differences were found between the UTV and LTV groups. LTV, lower thoracic vertebra; SRS, Scoliosis Research Society; UTV, upper thoracic vertebra.

necessitated revisions. O'Shaughnessy et $a l^{19}$ reported that eight patients underwent revision surgery for the following reasons: PJK (one patient), pseudarthrosis (five patients) and pedicle fracture and iliac screw removal (two patients). Kim et $a l^{20}$ reported that 31 patients underwent revision surgery for PJK (5 patients) or pseudarthrosis (21 patients). Fujimori et $a l^{21}$ reported that 7 of 38 revision surgeries were for PJK and 14 of 31 were for pseudarthrosis. Pseudarthrosis is the cause of the highest proportion of revision surgeries, and the subgroup meta-analyses for revision surgery due to pseudarthrosis and hardware implant failure showed no difference in the RR between the UTV and LTV groups. This might explain why no significant difference was found in total revision surgery between the two groups.

Posterior fixation extending into the upper thoracic region results in a longer operative time and greater intraoperative blood loss. In this meta-analysis, the operative time of the UTV group was significantly longer than that of the LTV group (WMD: 0.93, 95\% CI 0.48 to 1.39), and the UTV group had a greater estimated blood loss than did the LTV group. Most ASD patients are elderly, ${ }^{24}{ }^{25}$ and the increased number of fused segments might increase the implant cost and lengthen postoperative recovery. Individual surgical endurance levels and life expectancy ${ }^{41}$ should be considered before making surgical decisions in these cases. 
Study

ID
WMD $(95 \% \mathrm{Cl}) \quad$ Weight

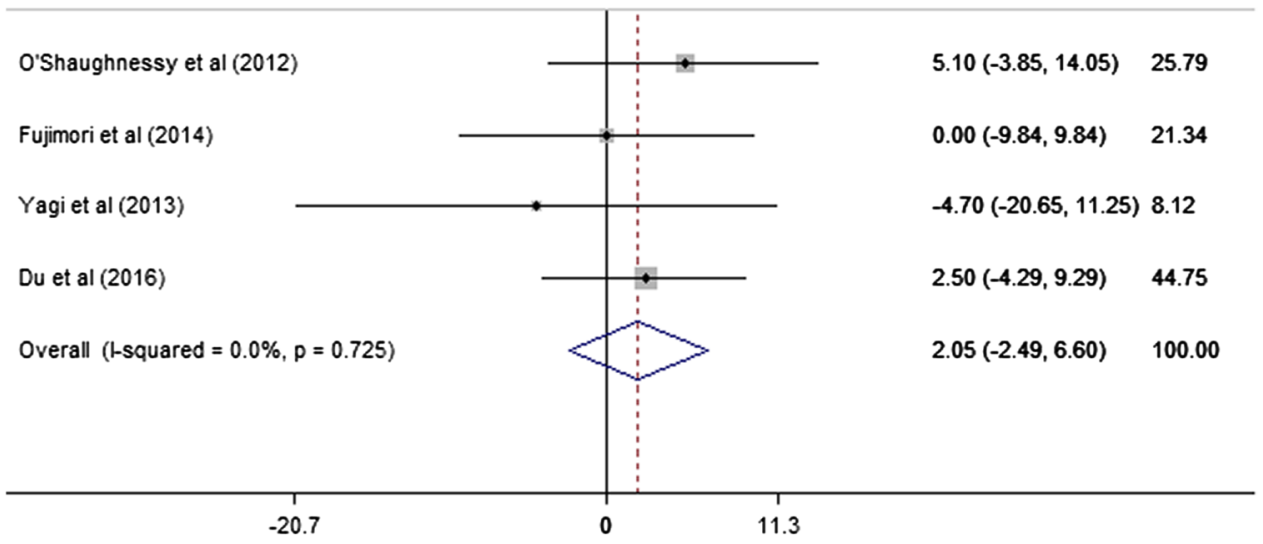

Figure 4 The meta-analysis results for the ODI score. No statistically significant difference between the UTV and LTV groups was found. LTV, lower thoracic vertebra; ODI, Oswestry disability index; UTV, upper thoracic vertebra.

\begin{tabular}{|c|c|c|}
\hline $\begin{array}{l}\text { Stovoly } \\
\text { ID }\end{array}$ & WMD (95\% CI) & $\begin{array}{l}\% \\
\text { Welgnt }\end{array}$ \\
\hline \multicolumn{3}{|l|}{ Thoracle kjphosls } \\
\hline Conet al (2013) & $1.68(-3.95,7.31)$ & 4329 \\
\hline KIm ex al (2007) & $5.66(-0.76,12.08)$ & 3324 \\
\hline Fujlmorl (2014) & $-1.00(-8.65,6.65)$ & 23.47 \\
\hline subcotal (l-squareo $-0.0 \%, p-0.404)$ & $2.37(-1.33,6.08)$ & 100.00 \\
\hline \multicolumn{3}{|l|}{ Thoracolumbar kyphosls } \\
\hline Cno et al (2013) & $-6.30(-11.11,-1.49)$ & 36.10 \\
\hline O' shaughnessy et al (2012) & $-10.20(-17.00,-3.40)$ & 29.02 \\
\hline Dues al (2016) & $0.40(-4.74 .5 .54)$ & 34.88 \\
\hline Subotal $(1-6 q u a r e d-70.2 \%, p-0.035)$ & $-5.09(-1094,0.75)$ & 100.00 \\
\hline \multicolumn{3}{|l|}{ Lumbar brossls } \\
\hline Cono ex al (2013) & $-3.50(-9.63,2.63)$ & 25.07 \\
\hline KIm ex al (2007) & $699(-0.24,14.22)$ & 21.66 \\
\hline Fullmorl (2014) & $5.00(-2.48,12.48)$ & 20.78 \\
\hline Duet al (2016) & $1.50(-3.52,6.52)$ & 31.49 \\
\hline Subotal (l-squared $-45.2 \%, p=0.134)$ & $2.11(-222,6.45)$ & 100.00 \\
\hline \multicolumn{3}{|l|}{ Proxlmal Junctional kyphotic angle } \\
\hline O'shaughnessy et al (2012) & $-5.20(-9.09,-1.31)$ & 24.59 \\
\hline KIm ex al (2007) & $5.32(1.23,9.41)$ & 24.07 \\
\hline Fujlmorl (2014) & $-3.00(-7.50,1.50)$ & 2299 \\
\hline Duet al (2016) & $1.50(-0.05,3.25)$ & 28.35 \\
\hline Subbotal (l-squared $-81.8 \%, p-0.001)$ & $-0.25(-4.49,396)$ & 100.00 \\
\hline \multicolumn{3}{|l|}{ C7 sagnal vertical axls } \\
\hline Conoes al (2013) & $40.53(19.70,61.36)$ & 2399 \\
\hline KIm ex al (2007) & $-35.57(-55.96,-15.16)$ & 24.15 \\
\hline FuJlmorl (2014) & $-22.00(-45.55,1.55)$ & 22.88 \\
\hline Du et al (2016) & $-0.50(-2.35,1.35)$ & 2898 \\
\hline Suchotal (1-6quares - $29.8 \%, p-0.000)$ & $-4.05(-28.51,20.42)$ & 100.00 \\
\hline \multicolumn{3}{|c|}{ C7 sag inal vertical axls (The study of Cho et al is omineo) } \\
\hline KInes al (2007) & $-35.57(-55.98,-15.16)$ & 31.15 \\
\hline FuJlmorl (2014) & $-22.00(-45.55,1.55)$ & 29.05 \\
\hline Duet al (2016) & $-0.50(-2.35,1.35)$ & 39.80 \\
\hline Subcotal (l-squared - $36.1 \%, p=0.001)$ & $-17.67(-42.01,6.67)$ & 100.00 \\
\hline \multicolumn{3}{|l|}{ PelMc incldence } \\
\hline Cono et al (2013) & $2.74(-2.45,793)$ & 48.60 \\
\hline FuJlmorl (2014) & $-2.00(-6.95,2.95)$ & 51.40 \\
\hline subotalal $(1-6 q u a r e d-40.5 \%, p-0.195)$ & $0.30(-4.34,495)$ & 100.00 \\
\hline \multicolumn{3}{|c|}{ NOTE: Welghts are from ranoom etects analjsils } \\
\hline & & \\
\hline-56 & & \\
\hline
\end{tabular}

Figure 5 The meta-analysis of the radiographic outcomes showed no significant differences between the UTV and LTV groups in terms of TK, TLK, LL, PJK angle, C7SVA, and pelvic incidence. C7SVA, C7 sagittal vertical axis; LTV, lower thoracic vertebra; LL, lumbar lordosis; PJK, proximal junctional kyphotic; TK, thoracic kyphosis; TLK, thoracolumbar kyphosis; UTV, upper thoracic vertebra. 


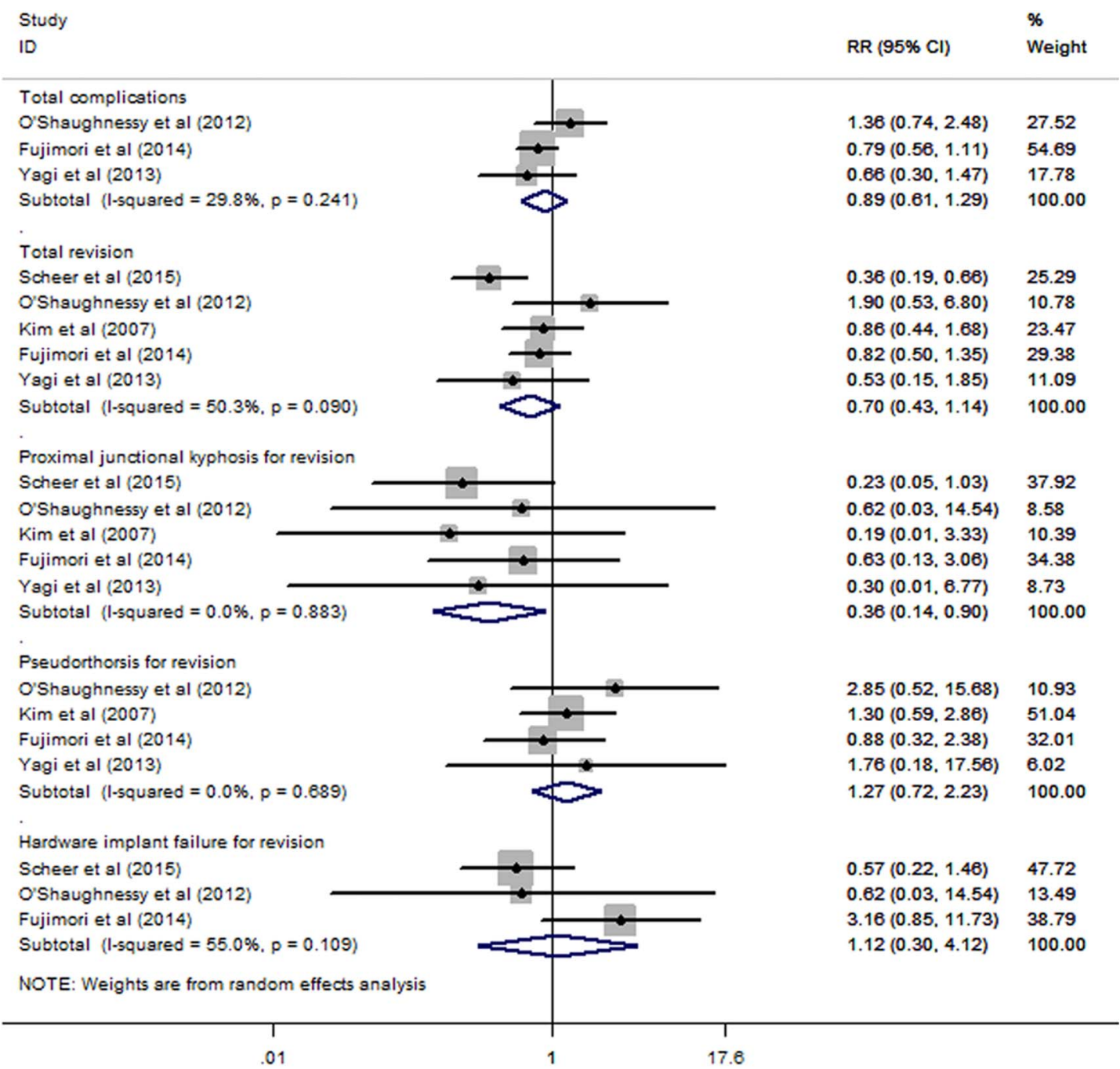

Figure 6 The meta-analyses of the total complications and revisions. No significant difference was found between the UTV and LTV groups for total complications and total revisions. The subgroup meta-analysis for revision surgery found that the UTV group had a lower risk of revision for PJK than the LTV group did (RR: 0.36; $95 \% \mathrm{Cl} 0.14$ to 0.90 ); however, no significant differences in pseudarthrosis or hardware implant failure for revision were found (RRs: $1.27(95 \% \mathrm{Cl} 0.72$ to 2.23$)$ and $1.12(95 \% \mathrm{Cl} 0.30$ to 4.12), respectively). LTV, lower thoracic vertebra; PJK, proximal junctional kyphotic angle; RR, relative risk; UTV, upper thoracic vertebra.

Another limitation is that there was no consistent definition of which vertebra constitutes UTV and which constitutes LTV. Clinically, the biomechanical transition region of the T11-L2 segment has always been regarded as the separating line by most surgeons; sites above this region were regarded as UTV, and those below it were considered LTV. To clarify to the readers how the UTV and LTV were determined in the studies included in this meta-analysis, the UTV and LTV designations for all of the included studies are listed in table 1 . The differences in these designations may have introduced heterogeneity into the present meta-analysis.

\section{Implications for future research and conclusions}

Current evidence shows that long posterior fixation extending into the upper thoracic region provides better correction of TLK and reduces the incidence of revision surgery related to PJK. Increasing the operative level results in longer operative times and a higher estimated blood loss. The UTV and LTV groups had similar outcomes in terms of SRS scores, ODI scores, total complications and the total number of revision surgeries. This initial analysis indicates that extending fixation to the upper thoracic region is appropriate in patients who are likely to develop PJK following the initial scoliosis correction. Additional high-quality studies (RCTs with larger sample sizes) using the same surgical intervention protocol and follow-up time are needed to decrease heterogeneity and to confirm the reported effects.

\section{Author affiliations}

${ }^{1}$ Department of Orthopaedics, Tianjin Hospital, Tianjin, China

${ }^{2}$ Division of Globus Medical, Musculoskeletal Education and Research Centre (MERC), Audubon, Pennsylvania, USA

${ }^{3}$ Department of Orthopaedics, Second Affiliated Hospital of Wenzhou Medical University, Zhejiang Spinal Research Centre, Wenzhou, Zhejiang, China 
Contributors $\mathrm{XF}, \mathrm{X}-\mathrm{LS}$ and A-MW conceived and designed the experiments. XF, X-LS, H-ZX, Y-LC and S-RS performed the experiments. XF, X-LS, H-ZX, $\mathrm{Y}-\mathrm{LC}$ and $\mathrm{S}-\mathrm{RS}$ analysed the data. XF, X-LS and A-MW contributed to reagents/materials/analysis tools. A-MW and JH wrote the paper. All authors critically revised the paper for intellectual content. XF and X-LS contributed equally to the manuscript as co-first authors.

Funding This work was supported by the National Natural Science Foundation of China (81501933); the Department of Science and Technology of Wenzhou, Wenzhou Science and Technology Project (2016Y0469); and the Xinmiao Talent Plan of Zhejiang Province (2014R413053). The funders had no role in the design or execution of the study or in the writing of the paper. The raw data can be found at http://dx.doi.org/10.6084/m9.figshare.1491414

Competing interests None declared.

Provenance and peer review Not commissioned; externally peer reviewed.

Data sharing statement Extra data can be accessed via the Dryad data repository at http://datadryad.org/ with the doi:10.5061/dryad.ns5hr

Open Access This is an Open Access article distributed in accordance with the terms of the Creative Commons Attribution (CC BY 4.0) license, which permits others to distribute, remix, adapt and build upon this work, for commercial use, provided the original work is properly cited. See: http:// creativecommons.org/licenses/by/4.0/

\section{REFERENCES}

1. Youssef JA, Orndorff DO, Patty CA, et al. Current status of adult spinal deformity. Global Spine J 2013;3:51-62.

2. Birknes JK, White AP, Albert TJ, et al. Adult degenerative scoliosis: a review. Neurosurgery 2008;63(3 Suppl):94-103.

3. Cho KJ, Kim YT, Shin SH, et al. Surgical treatment of adult degenerative scoliosis. Asian Spine J 2014;8:371-81.

4. Russo A, Bransford R, Wagner T, et al. Adult degenerative scoliosis insights, challenges, and treatment outlook. Curr Orthop Prac 2008;19:357-65.

5. Liu W, Chen XS, Jia LS, et al. The clinical features and surgical treatment of degenerative lumbar scoliosis: a review of 112 patients. Orthop Surg 2009;1:176-83.

6. Murray G, Beckman J, Bach K, et al. Complications and neurologica deficits following minimally invasive anterior column release for adult spinal deformity: a retrospective study. Eur Spine J 2015;24(Suppl 3):397-404.

7. Emami A, Deviren V, Berven S, et al. Outcome and complications of long fusions to the sacrum in adult spine deformity: luque-galveston, combined iliac and sacral screws, and sacral fixation. Spine 2002;27:776-86.

8. Maeda T, Buchowski JM, Kim YJ, et al. Long adult spinal deformity fusion to the sacrum using rhBMP-2 versus autogenous iliac crest bone graft. Spine 2009;34:2205-12.

9. Schwab FJ, Lafage V, Farcy JP, et al. Predicting outcome and complications in the surgical treatment of adult scoliosis. Spine 2008;33:2243-7.

10. Shufflebarger H, Suk SI, Mardjetko S. Debate: determining the upper instrumented vertebra in the management of adult degenerative scoliosis: stopping at T10 versus L1. Spine 2006;31(19 Suppl):S185-94.

11. Liberati A, Altman DG, Tetzlaff J, et al. The PRISMA statement for reporting systematic reviews and meta-analyses of studies that evaluate health care interventions: explanation and elaboration. $J$ Clin Epidemiol 2009;62:e1-34.

12. Slim K, Nini E, Forestier D, et al. Methodological index for nonrandomized studies (MINORS): development and validation of a new instrument. ANZ J Surg 2003:73:712-6.

13. Larsson SC, Orsini N, Wolk A. Vitamin B6 and risk of colorectal cancer: a meta-analysis of prospective studies. JAMA 2010;303:1077-83.

14. DerSimonian R, Laird N. Meta-analysis in clinical trials. Control Clin Trials 1986;7:177-88.

15. Wu AM, Sun XL, Lv QB, et al. The relationship between dietary protein consumption and risk of fracture: a subgroup and dose-response meta-analysis of prospective cohort studies. Sci Rep 2015;5:9151.

16. Yagi $M$, King $A B$, Cunningham ME, et al. Long-term clinical and radiographic outcomes of pedicle subtraction osteotomy for fixed sagittal imbalance: does level of proximal fusion affect the outcome? Minimum 5-year follow-up. Spine Deformity 2013;1:123-31.
17. Cho KJ, Suk SI, Park SR, et al. Selection of proximal fusion level for adult degenerative lumbar scoliosis. Eur Spine J 2013;22:394-401.

18. Scheer JK, Lafage V, Smith JS, et al. Maintenance of radiographic correction at 2 years following lumbar pedicle subtraction osteotomy is superior with upper thoracic compared with thoracolumbar junction upper instrumented vertebra. Eur Spine J 2015;24(Suppl 1): S121-30.

19. O'Shaughnessy BA, Bridwell KH, Lenke LG, et al. Does a long-fusion "T3-sacrum" portend a worse outcome than a short-fusion "T10-sacrum" in primary surgery for adult scoliosis? Spine 2012;37:884-90.

20. Kim YJ, Bridwell KH, Lenke LG, et al. Is the T9, T11, or L1 the more reliable proximal level after adult lumbar or lumbosacral instrumented fusion to L5 or S1? Spine 2007;32:2653-61.

21. Fujimori $\mathrm{T}$, Inoue $\mathrm{S}$, Le $\mathrm{H}$, et al. Long fusion from sacrum to thoracic spine for adult spinal deformity with sagittal imbalance: upper versus lower thoracic spine as site of upper instrumented vertebra. Neurosurg Focus 2014;36:E9.

22. Du J, Tang X, Li N, et al. Limited long-segment fusion for degenerative lower lumbar scoliosis: a special kind of scoliosis. Int Orthop 2016;40:1227-31.

23. Tribus CB. Degenerative lumbar scoliosis: evaluation and management. J Am Acad Orthop Surg 2003;11:174-83.

24. Kim JH, Suk SI, Chung ER, et al. Epidemiologic study of lumbar scoliosis with plain abdominal X-ray. J Korean Soc Spine Surg 2004;11:246-52.

25. Kostuik JP, Bentivoglio J. The incidence of low-back pain in adult scoliosis. Spine 1981;6:268-73.

26. Schwab F, Lafage V, Farcy JP, et al. Surgical rates and operative outcome analysis in thoracolumbar and lumbar major adult scoliosis: application of the new adult deformity classification. Spine 2007;32:2723-30.

27. Simmons ED. Surgical treatment of patients with lumbar spinal stenosis with associated scoliosis. Clin Orthop Relat Res 2001 (384):45-53.

28. Berven S, Deviren V, Demir-Deviren S, et al. Studies in the modified Scoliosis Research Society Outcomes Instrument in adults: validation, reliability, and discriminatory capacity. Spine 2003;28:2164-9; discussion 69.

29. Farcy JP, Schwab FJ. Management of flatback and related kyphotic decompensation syndromes. Spine 1997;22:2452-7.

30. Zhu F, Bao H, Liu Z, et al. Unanticipated revision surgery in adult spinal deformity: an experience with 815 cases at one institution. Spine 2014;39(26 Spec No.):B36-44.

31. Baghdadi YM, Larson AN, Dekutoski MB, et al. Sagittal balance and spinopelvic parameters after lateral lumbar interbody fusion for degenerative scoliosis: a case-control study. Spine 2014;39: E166-73.

32. Acosta FL, Liu J, Slimack N, et al. Changes in coronal and sagittal plane alignment following minimally invasive direct lateral interbody fusion for the treatment of degenerative lumbar disease in adults: a radiographic study. J Neurosurg Spine 2011;15:92-6.

33. Zurbriggen $\mathrm{C}$, Markwalder TM, Wyss S. Long-term results in patients treated with posterior instrumentation and fusion for degenerative scoliosis of the lumbar spine. Acta Neurochir (Wien) 1999;141:21-6.

34. Bridwell $\mathrm{KH}$. Selection of instrumentation and fusion levels for scoliosis: where to start and where to stop. Invited submission from the Joint Section Meeting on Disorders of the Spine and Peripheral Nerves. J Neurosurg Spine 2004;1:1-8.

35. Luhmann SJ, Lenke LG, Bridwell KH, et al. Revision surgery after primary spine fusion for idiopathic scoliosis. Spine 2009;34:2191-7.

36. Kim YJ, Bridwell KH, Lenke LG, et al. Proximal junctional kyphosis in adult spinal deformity after segmental posterior spinal instrumentation and fusion: minimum five-year follow-up. Spine 2008;33:2179-84.

37. Ghiselli G, Wang JC, Bhatia NN, et al. Adjacent segment degeneration in the lumbar spine. J Bone Joint Surg Am 2004;86-A:1497-503.

38. Wu AM, Ni WF, Weng W, et al. Outcomes of percutaneous kyphoplasty in patients with intravertebral vacuum cleft. Acta Orthop Belg 2012;78:790-5.

39. Lau D, Clark AJ, Scheer JK, et al. Proximal junctional kyphosis and failure after spinal deformity surgery: a systematic review of the literature as a background to classification development. Spine 2014;39:2093-102.

40. Hyun SJ, Kim YJ, Rhim SC. Patients with proximal junctional kyphosis after stopping at thoracolumbar junction have lower muscularity, fatty degeneration at the thoracolumbar area. Spine J 2016;16:1095-101.

41. Silva FE, Lenke LG. Adult degenerative scoliosis: evaluation and management. Neurosurg Focus 2010;28:E1. 